\title{
Brazilian Mineral Clays: Classification, Acid Activation and Application as Catalysts for Methyl Esterification Reactions
}

\author{
Laís P. Dill, ${ }^{a}$ Débora M. Kochepka, ${ }^{a}$ Larissa L. Lima, ${ }^{\circledR b}{ }^{b}$ Alexandre A. Leitão, ${ }^{b}$ \\ Fernando Wypych ${ }^{\circledR a}$ and Claudiney S. Cordeiro ${ }^{\circledR *, a}$
}

${ }^{a}$ Departamento de Química, Universidade Federal do Paraná (UFPR), CP 19061, 81531-980 Curitiba-PR, Brazil

${ }^{b}$ Departamento de Química, Universidade Federal de Juiz de Fora (UFJF), 36033-330 Juiz de Fora-MG, Brazil

\begin{abstract}
In this study, three raw Brazilian clays from João Pessoa, Paraíba State (Aço AP, AVL and Verde Lodo) were characterized before and after purification and acid activation. Several instrumental techniques were used, and the raw clays were classified as dioctahedral smectites with different compositions, where the AVL sample had the highest content of montmorillonite. In addition, analyses showed modification in clay mineral compositions, mainly due to removal of impurities and octahedral sheet cation leaching during acid activation, which resulted in specific areas ranging from 42 to $93 \mathrm{~m}^{2} \mathrm{~g}^{-1}$ and increase of the Brønsted/Lewis acid site ratio, until 1.52 (AVL). Then, methyl esterification reactions were performed using the acid-activated clays as catalysts. The maximum acid conversions obtained were of 92 and $64 \%$, for acetic acid using activated AVL and for lauric acid using activated Verde Lodo, respectively, and these data were correlated mainly to the Brønsted-Lowry acidity.
\end{abstract}

Keywords: montmorillonite, surface acidity, catalysis, methanolysis

\section{Introduction}

Clay minerals are hydrated layered aluminum silicates containing different amounts of iron, magnesium and alkaline metal cations, found abundantly in nature, which makes them inexpensive. In clay minerals' structure, tetrahedral sheets are composed of $\mathrm{SiO}_{4}$ units, and octahedral sheets of $\mathrm{M}(\mathrm{OH})_{6}$ can be formed by two different structural arrangements depending on the central cation. When the central cation is trivalent, usually $\mathrm{Al}^{3+}$, the sheets are dioctahedral, where one-third of the octahedral sites are empty, while if it is bivalent, such as $\mathrm{Mg}^{2+}$, the sheets are trioctahedral, where all the octahedral sites are occupied. Furthermore, the tetrahedral ( $\mathrm{T}$ ) and octahedral $(\mathrm{O})$ sheets are linked together forming layers that are packed along the basal direction, resulting in a layered structure, by which clay minerals can be classified mainly in two groups, 1:1 (T:O) and 2:1 (T:O:T). The most abundant clays in nature are smectites $(2: 1)$ and kaolins $(1: 1){ }^{1}$

Raw clays are not composed of only one type of mineral. Instead, they are mixed with associated minerals, such as

*e-mail: claudiney.cordeiro@ufpr.br talc, dolomite, calcite and quartz. In general, clays have small particle size (less than $2 \mu \mathrm{m}$ ), distinct specific areas (from 15 to $150 \mathrm{~m}^{2} \mathrm{~g}^{-1}$ ) and different cation exchange capacities (between 3 and 150 meq per $100 \mathrm{~g}$ ). Moreover, clay minerals contain hydroxide groups, Brønsted-Lowry acid sites (external $\mathrm{OH}$ ) and Lewis acid sites (unsaturated tetrahedral $\mathrm{Al}^{3+}$ ). Thus, these materials are useful for several applications in agriculture, ceramics and cosmetics, among many examples. Also, the properties of these solids can be altered or improved through chemical modifications, to enable their use as inexpensive adsorbents and catalysts. ${ }^{2-4}$

The most common chemical modifications of clay minerals include intercalation of organic cations, pillarization with metal oxides, and basic or acid activation. Among these treatments, acid activation is a useful tool to obtain materials with modified specific areas, porosity and acidity, which are interesting for use in catalysis. This process can be performed with organic or inorganic acids and may simply involve the mixing of the solid with an acid solution under heating or at room temperature. Therefore, both the reaction conditions (acid solution concentration, acid:clay ratio, time and temperature) and the composition of the material are responsible for the results of clay 
activation, since, for example, $\mathrm{Mg}-\mathrm{O}$ and $\mathrm{Fe}-\mathrm{O}$ bonds are weaker than $\mathrm{Al}-\mathrm{O}$, leading to easier leaching of $\mathrm{Mg}$ and Fe during acid attack..$^{2,5-8}$

During acid activation, the exchangeable cations are replaced by hydrated protons, after which the hydrated protons permeate the clay mineral layers and attack structural $\mathrm{OH}$ groups, causing leaching of the central atoms (aluminum, magnesium or iron) from the tetrahedral and octahedral sheets at similar rates. This extensive process of clay dissolution leads to different amounts of three-dimensional amorphous hydrated silica. Moreover, the resulting material can have Brønsted acid sites obtained from hydrated protons and formation of silanol, aluminol and magnesol on the edges of the clays, as well as Lewis acid sites from tetrahedral $\mathrm{Al}^{3+}$ exposed on the edges. ${ }^{6,8}$

Researchers ${ }^{9-13}$ have reported the acid activation of different clays (kaolinite, montmorillonite, saponite, palygorskite) as well commercially available acid-activated montmorillonites (montmorillonite K10 and KSF) for the catalysis of reactions that requires acid sites. Therefore, acid-activated clays can be used as catalysts for important chemical processes, like esterification reactions, whose products have many applications, such as biofuels, surfactants, plasticizer additives and lubricants. ${ }^{14,15}$ For instance, Timofeeva et al..$^{16}$ showed that the activation of a raw montmorillonite with $0.5 \mathrm{~mol} \mathrm{~L}^{-1}$ of $\mathrm{HNO}_{3}$ solution by 7 days at room temperature resulted in a material with fitted properties for the synthesis of solketal. This because, when the activated solid was used in the reaction between glycerol and acetone at the molar ratio of $1: 4.1$ at $50{ }^{\circ} \mathrm{C}$ by $30 \mathrm{~min}$, the selectivity of solketal was around $90 \%$ and the catalyst was reused for three times.

Zatta et al. ${ }^{17}$ performed the activation of a montmorillonite with $\mathrm{H}_{3} \mathrm{PO}_{4}$ under reflux conditions using different acid solution concentrations $(0.5,1,2$ and $\left.4 \mathrm{~mol} \mathrm{~L}^{-1}\right)$ and several reaction times (1, 2, 3 and $\left.4 \mathrm{~h}\right)$. The resulting structural properties achieved were dependent on the acid concentration, since at concentrations above $1 \mathrm{~mol} \mathrm{~L}^{-1}$, the octahedral cation leaching was high, obtaining larger amounts of amorphous silica, which caused lower specific areas and pore volumes in relation to the milder conditions. Furthermore, the catalysts produced were used in the methyl esterification of lauric acid and the best result $(96.6 \%$ esters) was achieved with the clay activated with the $0.5 \mathrm{~mol} \mathrm{~L}^{-1}$ acid solution for $2 \mathrm{~h}$. The authors attributed that to the lower leaching of $\mathrm{Al}$ and $\mathrm{Mg}$, which provided a material with adequate specific area, pore volume and acidity. Moreover, the solid was recovered and reused for four consecutive reaction cycles with virtually all the catalytic activity preserved.
The above-mentioned issues related to the abundancy of smectite clays and their catalytic properties improved after acid activation encourage this study. Furthermore, the use of $\mathrm{H}_{3} \mathrm{PO}_{4}$ for the clay treatment was chosen due to its previous reported efficiency ${ }^{17}$ and to the advantage of phosphate residues being used in fertilizers. According to this, the aim of this study was to evaluate the properties of three raw Brazilian clay minerals before and after their purification, and then after their activation with phosphoric acid for several techniques by a critical evaluation that is scarce in literature. In addition, the use of acid clays in catalysis is clearly advantageous, since they are materials that generally have low production cost and are environmentally friendly because it is possible to recover and reuse the catalyst, which reduces residues and process costs. Furthermore, the catalytic activity of those acid clays was studied for the methyl esterification of acetic acid and lauric acid with the purpose of correlating the catalytic results with the catalyst properties, which showed a strong influence of Brønsted-Lowry acid sites for these Brazilian acid-activated clays not published before.

\section{Experimental}

The three raw clays were donated by Bentonisa do Nordeste (Boa Vista, Brazil), called Aço AP, AVL and Verde Lodo. These are respectively designated in this study as AP, AV and VL (before purification), PAP, PAV and PVL (after purification), and HAP, HAV, HVL (after purification and acid activation). Commercial montmorillonite $\mathrm{K}-10^{\circledR}$ was provided by Sigma-Aldrich (St. Louis, USA). Hydrogen peroxide (30 vol\%) and phosphoric acid (85 wt.\%) were obtained from Neon (Lahore, Pakistan). Acetic acid, lauric acid and methanol were purchased from Merck (St. Louis, USA). All other reactants and solvents used in the experiments were acquired with the quality described in the methods.

Raw clays were purified using $30 \mathrm{vol} \%$ hydrogen peroxide $\left(\mathrm{H}_{2} \mathrm{O}_{2}\right)$ at the proportion of 1:3 (clay $(\mathrm{g}): \mathrm{H}_{2} \mathrm{O}_{2}$ $(\mathrm{mL})$ ), followed by elutriation under $\mathrm{N}_{2}$ flow and submitted to acid activation with a $0.5 \mathrm{~mol} \mathrm{~L}^{-1} \mathrm{H}_{3} \mathrm{PO}_{4}$ solution at the proportion of 1:4 (clay $(\mathrm{g}): \mathrm{H}_{3} \mathrm{PO}_{4}$ solution $(\mathrm{mL})$ ), as described in a previous publication..$^{18}$

Raw, purified and acid-activated clays were characterized by several instrumental techniques. X-ray fluorescence (XRF) measurements were carried out with a PANalytical Axios $^{\mathrm{mAX}}$ spectrometer, with $3 \mathrm{~kW}$ tube and rhodium target $(\mathrm{Rh})$. For this purpose, samples were ground in a pulverizer for $30 \mathrm{~s}$ and dried in an oven at $105{ }^{\circ} \mathrm{C}$ for $24 \mathrm{~h}$. Then $7 \mathrm{~g}$ of ground solid and $1.4 \mathrm{~g}$ of $\mathrm{Li}_{2} \mathrm{~B}_{4} \mathrm{O}_{7}$ from Sigma-Aldrich (St. Louis, USA) were used to make a pellet, whose chemical composition was determined. 
Loss to fire (L.F.) was measured with samples weighing about $2 \mathrm{~g}$ placed in a porcelain crucible and submitted to $1000{ }^{\circ} \mathrm{C}$ for $2 \mathrm{~h}$. Percentage of lost material was obtained from the difference between the weight of the crucible containing ash and the empty one.

Thermogravimetric analysis (TGA) and derived thermogravimetric analysis (DTG) were performed with a Netzsch STA449F3 Jupiter analyzer. Samples weighing approximately $5 \mathrm{mg}$ were deposited in aluminum oxide crucibles and exposed to synthetic air atmosphere at $50 \mathrm{~mL} \mathrm{~min}{ }^{-1}$ flow and heated at $10^{\circ} \mathrm{C} \mathrm{min}^{-1}$.

Fourier transform infrared spectra (FTIR) were recorded in transmission mode with a Bomem Michelson MB1000 series spectrometer. Pellets were prepared with $1 \%\left(\mathrm{~m} \mathrm{~m}^{-1}\right)$ of sample in dried $\mathrm{KBr}$ of $99 \%$ purity from Sigma-Aldrich (St. Louis, USA). Analyses were carried out in the wavenumber range of $4000-400 \mathrm{~cm}^{-1}$, with resolution of $2 \mathrm{~cm}^{-1}$ and accumulation of 32 scans.

Powder X-ray diffraction (XRD) analysis of the samples deposited on glass sample holders was performed in reflection mode in a Shimadzu XRD-6000 diffractometer with $\mathrm{Cu} K \alpha$ radiation source $(40 \mathrm{kV}, 20 \mathrm{~mA}$, $\lambda=0.15418 \mathrm{~nm}$ ), with scan speed of $2^{\circ} \mathrm{min}^{-1}$ and step of $0.02^{\circ}$. Meanwhile, the specific purified clay minerals were characterized by the steps described below. The basal distances, that are $\mathrm{d}(001)$, were obtained by the analysis of the samples dried at $105^{\circ} \mathrm{C}$, calcined at $550{ }^{\circ} \mathrm{C}$ for $2 \mathrm{~h}$ and subjected to $\mathrm{Mg}^{2+}$ cation exchange $\left(\mathrm{MgCl}_{2}\right.$, Sigma-Aldrich, St. Louis, USA) followed by saturation with ethylene glycol (Neon, Lahore, Pakistan). Calculation of the basal distances was also performed on samples subjected to $\mathrm{Li}^{+}$ cation exchange ( $\mathrm{LiCl}$, Sigma-Aldrich, St. Louis, USA) followed by saturation with ethylene glycol, according to the literature..$^{19,20}$

$\mathrm{N}_{2}$ adsorption-desorption isotherms were obtained with a Quantachrome Nova 2000e gas sorption analyzer. The samples were previously degassed under vacuum at $150{ }^{\circ} \mathrm{C}$ for $2 \mathrm{~h}$ and analyses were performed under liquid nitrogen $\left(-196{ }^{\circ} \mathrm{C}\right)$. The Brunauer-Emmet-Teller (BET) method was applied to calculate specific area, while the Barrett-Joyner-Halenda (BJH) model was used to obtain pore volume and average size from desorption isotherms.

Magic angle spinning-nuclear magnetic resonance (MAS-NMR) spectra were obtained with a Bruker Avance III HD spectrometer operating in a field of $7.04 \mathrm{~T}$ (78.9 MHz), with a CPMAS probe with two channels and $4 \mathrm{~mm}$ zirconia rotors. ${ }^{27} \mathrm{Al}$ analysis $\left({ }^{27} \mathrm{Al} \mathrm{NMR}\right)$ was carried out with a single pulse experiment, with pulse of $\pi / 6$ of $1.33 \mu \mathrm{s}$, recycle interval between pulses of $1.0 \mathrm{~s}$ and 1024 acquisitions. In these runs, samples were spun at $10000 \mathrm{~Hz}$ and the external reference used was $\mathrm{AlCl}_{3} \cdot 6 \mathrm{H}_{2} \mathrm{O}$ solid from Sigma-Aldrich (St. Louis, USA) $\left({ }^{27} \mathrm{Al}\right.$, $\mathrm{d}=0.0 \mathrm{ppm}) .{ }^{29} \mathrm{Si}$ core spectra $\left({ }^{29} \mathrm{Si} \mathrm{NMR}\right)$ were acquired by HPDEC (high-power decoupling pulse) analysis, with pulse of $3.35 \mu \mathrm{s}$, pulse intervals of $10 \mathrm{~s}$ and 3072 acquisitions. In this case, the external reference was solid kaolinite $\left(\mathrm{Al}_{2} \mathrm{Si}_{2} \mathrm{O}_{5}(\mathrm{OH})_{4}\right)$ from Sigma-Aldrich (St. Louis, USA) $\left({ }^{29} \mathrm{Si}, \mathrm{d}=-91.5 \mathrm{ppm}\right)$ and samples were spun at $5000 \mathrm{~Hz}$.

Characterization of Lewis and Brønsted-Lowry acid sites was carried by the adsorption of pyridine from SigmaAldrich (St. Louis, USA) in the samples and measurement by diffuse reflectance infrared Fourier-transform spectroscopy (DRIFT). Spectra were acquired with a Bruker Vertex 70 spectrometer in the range of $4000-400 \mathrm{~cm}^{-1}$, accumulation of 32 spectra, with resolution of $2 \mathrm{~cm}^{-1}$. Before the analysis, the sample was submitted to desorption thermal treatment at $350{ }^{\circ} \mathrm{C}$ for $2 \mathrm{~h}$ and immediately exposed to a pyridinesaturated atmosphere until reaching equilibrium. The physiosorbed molecules were removed under $\mathrm{N}_{2}$ flux and then the spectra were obtained. Concentrations of Lewis $\left(1450 \mathrm{~cm}^{-1}\right)$ and Brønsted-Lowry $\left(1538 \mathrm{~cm}^{-1}\right)$ acid sites were calculated by equations 1 and 2.21,22

$$
\begin{aligned}
& \mathrm{C}=\frac{1.67 \mathrm{IA}(\mathrm{B}) \mathrm{R}^{2}}{\mathrm{M}} \\
& \mathrm{C}=\frac{2.22 \mathrm{IA}(\mathrm{L}) \mathrm{R}^{2}}{\mathrm{M}}
\end{aligned}
$$

where: $\mathrm{C}$ is the concentration of pyridine in $\mu \mathrm{mol}$ per $\mathrm{g}$ of solid; IA(B) or IA(L) is the integrated area of the transmittance band of B (Brønsted-Lowry) or L (Lewis); $\mathrm{R}$ is the radius of the sample holder $(\mathrm{cm})$; $\mathrm{M}$ is the mass of the sample (mg).

Density of Lewis and Brønsted-Lowry acid sites was calculated by equation 3 :

$\mathrm{D}=\left(\frac{\mathrm{C}}{\mathrm{SA}}\right)$

where: $\mathrm{D}$ is the density of pyridine in $\mu \mathrm{mol}$ per $\mathrm{m}^{2}$ of solid; $\mathrm{C}$ is the concentration of pyridine in $\mu$ mol per $\mathrm{g}$ of solid from Brønsted-Lowry or Lewis acid sites; SA is the specific area of the sample $\left(\mathrm{m}^{2}\right)$.

Reactions between methanol and acetic or lauric acid catalyzed by the acid-activated clays were carried out in a Teflon autoclave reactor with capacity of $15 \mathrm{~mL}$. The reactor was covered with a metallic jacket and inserted in an oil bath heated to $120^{\circ} \mathrm{C}$ and magnetically stirred at $500 \mathrm{rpm}$ for $2 \mathrm{~h}$. The methanol:carboxylic acid molar ratio was $3: 1$ and the catalyst, that was previously dried at $200^{\circ} \mathrm{C}$ for $2 \mathrm{~h}$, was used in the proportion of $5 \mathrm{wt} . \%$ in relation 
to the carboxylic acid mass. The same reaction conditions were used to perform reactions with the purified AP (before acid-activation) and with commercial montmorillonite K10 (K10). Furthermore, a control reaction was performed in the absence of catalyst, under the same conditions. After the reactions, the samples were filtered to remove the solid catalyst. Then, aliquots of approximately $35 \mathrm{mg}$ were solubilized in $10 \mathrm{~mL}$ of ethanol (Sigma-Aldrich, St. Louis, USA) and titrated with $0.1 \mathrm{~mol} \mathrm{~L}^{-1} \mathrm{NaOH}$ (Neon, Lahore, Pakistan) solution, standardized using potassium biphthalate, based on the American Oil Chemists' Society method AOCS Ca $5 \mathrm{a}-40 .^{23}$ The percentage of acid consumed (CA) was determined by the difference between the calculated percentages of initial acid (IA) and of unreacted free acid (FA).

The reuse of the catalyst after one reaction cycle was investigated. After use, the catalyst was filtered and washed three times under reflux with a mixture of ethanol:hexane $\left(1: 1 \mathrm{v} \mathrm{v}^{-1}\right)$, both from Sigma-Aldrich (St. Louis, USA). The solid was dried in an oven at $250{ }^{\circ} \mathrm{C}$ for $2 \mathrm{~h}$ and analyzed by FTIR and XRD. Afterwards, the dried catalyst was used in a new reaction cycle.

Statistical analyses of the results obtained for acid conversion were performed with the GraphPad Prism 5 software ${ }^{24}$ by applying the Tukey test at $95 \%$ confidence level.

\section{Results and Discussion}

\section{Characterization of natural, purified and acid-activated clays}

Although clay purification procedure adopted in this study is not sufficient for obtaining pure and maximum enrichment of montmorillonite clay mineral, it was used to facilitate clay characterization and use by the diminishing of quartz and organic matter. X-ray diffractogram and FTIR spectra of raw, purified and acid-activated clays are shown in Figure 1. XRD patterns of the raw samples AP, AV and VL (Figures 1A, 1B, 1C, curve a) indicated quartz $(\mathrm{Q})$ as the main impurity.

Moreover, the first basal reflection was used to calculate the basal distances $(\mathrm{d}(001))$, which were the same in the samples before and after purification (Figures 1A, 1B, 1C, curves a and b): $14.03,14.98$ and $15.24 \AA$ for AV, AP and $\mathrm{VL}$, respectively. These values can be related to the fact that smectite has sodium as interlayer cation with two layers of hydration in each unitary cell. The presence of $\mathrm{Na}^{+}$as interlayer cation was also observed by $\mathrm{d}(001)$ reflection in the study of Krupskaya et al. ${ }^{25}$ in the montmorillonites from the Taganskoye deposit in Kazakhstan. Despite the evidence of a large amount of smectite in the samples, clays can be a mixture of many different minerals, ${ }^{26}$ so each type needs mineralogical classification.

Since the clays were basically composed by smectites, we investigated whether the smectites were dioctahedral or trioctahedral, which was done by measuring the interplanar distance using the 060 reflection, that is $\mathrm{d}(060)$, as shown in Figures 1A, 1B, 1C, curve a $(1.50,1.50$ and $1.50 \AA$ for $\mathrm{AV}, \mathrm{AP}$ and $\mathrm{VL}$, respectively, which correspond to the $\mathrm{b}$ cell parameters of 8.99, 9.01 and 9.01 ).

These values correspond to those expected for dioctahedral smectites and Krupskaya et al. ${ }^{27}$ came the same conclusion, since the interplanar distance of the 060 reflection obtained for two samples of bentonites, Al-rich from Trebia deposit (Morocco) and Fe-rich from Podgornoe deposit (Russia), that presented the $\mathrm{d}(060)$ values of 1.49 and $1.50 \AA$, respectively. Also, it was corroborated because the $\mathrm{b}$ cell parameter to dioctahedral smectites are close to $9 \AA$, while in trioctahedral smectites the b cell parameter should be $9.2 \AA .28$

FTIR spectra of the raw mineral clays (Figures 1D, $1 \mathrm{E}, 1 \mathrm{~F}$, curve a) presented bands regarding structural hydroxyls, mainly octahedral aluminum at $3631 \mathrm{~cm}^{-1}, \mathrm{O}-\mathrm{H}$ from hydration water $\left(3440 \mathrm{~cm}^{-1}\right)$ and angular deformation of $\mathrm{O}-\mathrm{H}$ from water $\left(1643 \mathrm{~cm}^{-1}\right)$. Furthermore, the band at $1035 \mathrm{~cm}^{-1}$ was related to $\mathrm{Si}-\mathrm{O}$ stretching, indicating the presence of dioctahedral smectites, since the $\mathrm{Si}-\mathrm{O}$ stretching of dioctahedral was observed in the region of 1030 to $1019 \mathrm{~cm}^{-1}$ and that of trioctahedral in the region of 1009 to $1012 \mathrm{~cm}^{-1}$. This observation is supported by the absence of a band at $844 \mathrm{~cm}^{-1}$, assigned to $\mathrm{Al}-\mathrm{OH}-\mathrm{Mg}$ deformation related to trioctahedral smectite..$^{29}$ Besides that, bands were observed at 524 and $466 \mathrm{~cm}^{-1}$, attributed to vibration of $\mathrm{Al}-\mathrm{O}-\mathrm{Si}$ and $\mathrm{Si}-\mathrm{O}-\mathrm{Si}$, respectively, the first characteristic of octahedral $\mathrm{Al}$ and the second of free silica, also corroborated by the bands at 694 and $793 \mathrm{~cm}^{-1} .30,31$

The smectite presence was then assessed through two treatments, cation exchange with $\mathrm{MgCl}_{2}$ followed by ethylene glycol saturation, calcination at $550^{\circ} \mathrm{C}$ for $2 \mathrm{~h}$. The basal spaces obtained before and after these treatments are shown in Figures 2A, 2B and 2C. The results obtained were as expected for smectite clays, since there was an increase of the basal distance in the samples saturated with ethylene glycol (15.46 $\AA$ for AV, $16.81 \AA$ for AP and $16.98 \AA$ for $\mathrm{VL}$ ), in all cases assigned to basal spacing of smectites with two layers of ethylene glycol in the interlayer space. Besides that, the calcination promoted structural collapse and consequent basal distance reduction $(9.79 \AA$ for $\mathrm{AV}$, $9.89 \AA$ for AP and $9.88 \AA$ for VL). ${ }^{32}$

To distinguish between the dioctahedral smectites (montmorillonite, nontronite and beidellite), the Greene-Kelly method ${ }^{19}$ was used, in which the sample was exchanged with 

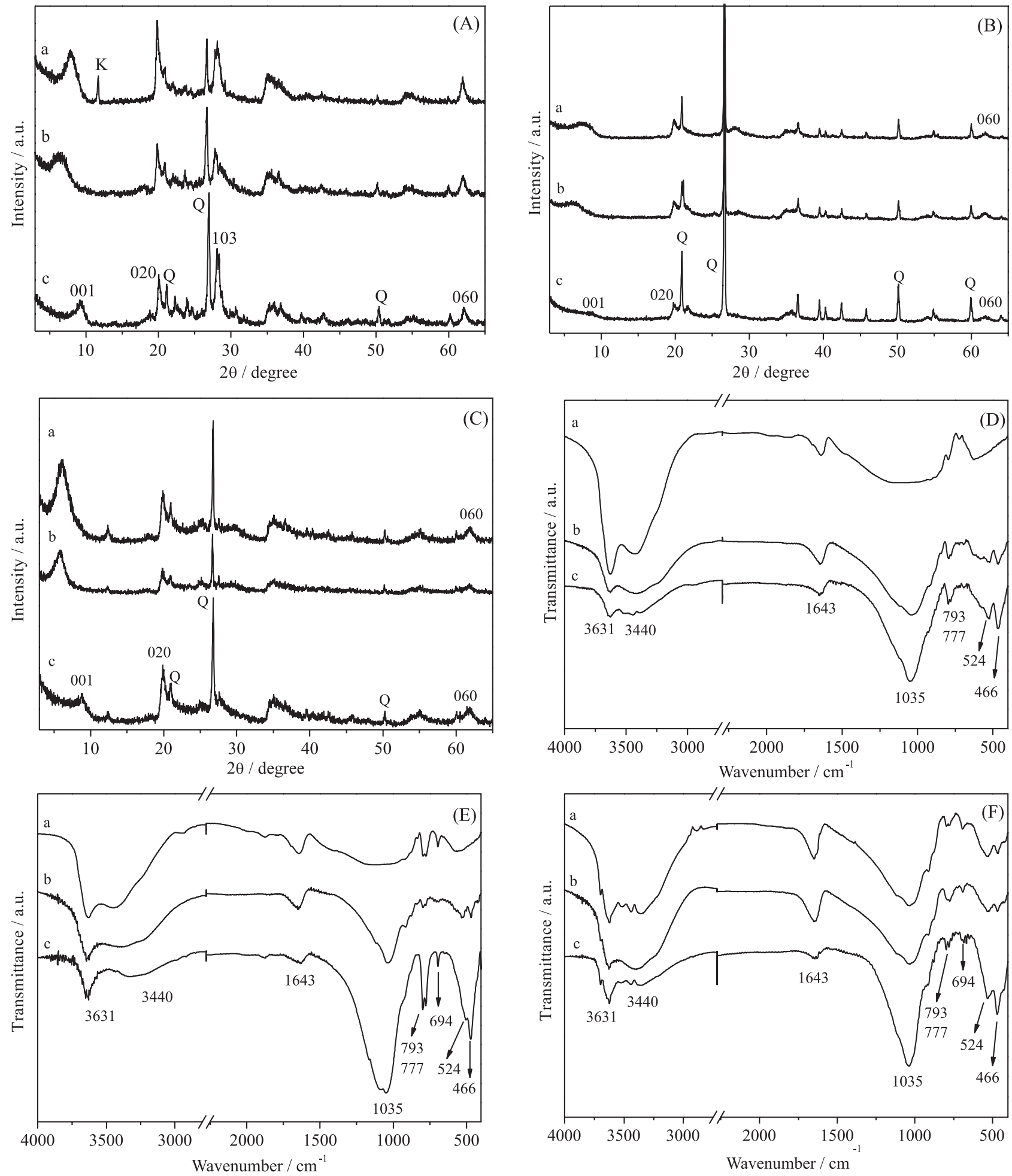

Figure 1. XRD patterns and FTIR spectra, respectively for (A, D) AV, (B, E) AP and (C, F) VL. The lowercase letters correspond to (a) raw, (b) purified and (c) acid-activated mineral clays.

$\mathrm{LiCl}$, followed by ethylene glycol saturation. Thus, $\mathrm{Li}^{+}$ permeates the montmorillonite structure and occupies the empty octahedral sites, preventing the clay from swelling when in ethylene glycol atmosphere, which does not modify its basal spacing. On the other hand, in beidellites and nontronites, there are no vacant octahedral sites, so the clay mineral swells after ethylene glycol saturation, significantly increasing the basal spacing. ${ }^{19,20}$

XRD patterns obtained after $\mathrm{Li}^{+}$exchange and $\mathrm{Li}^{+}$ exchange followed by ethylene glycol saturation are 

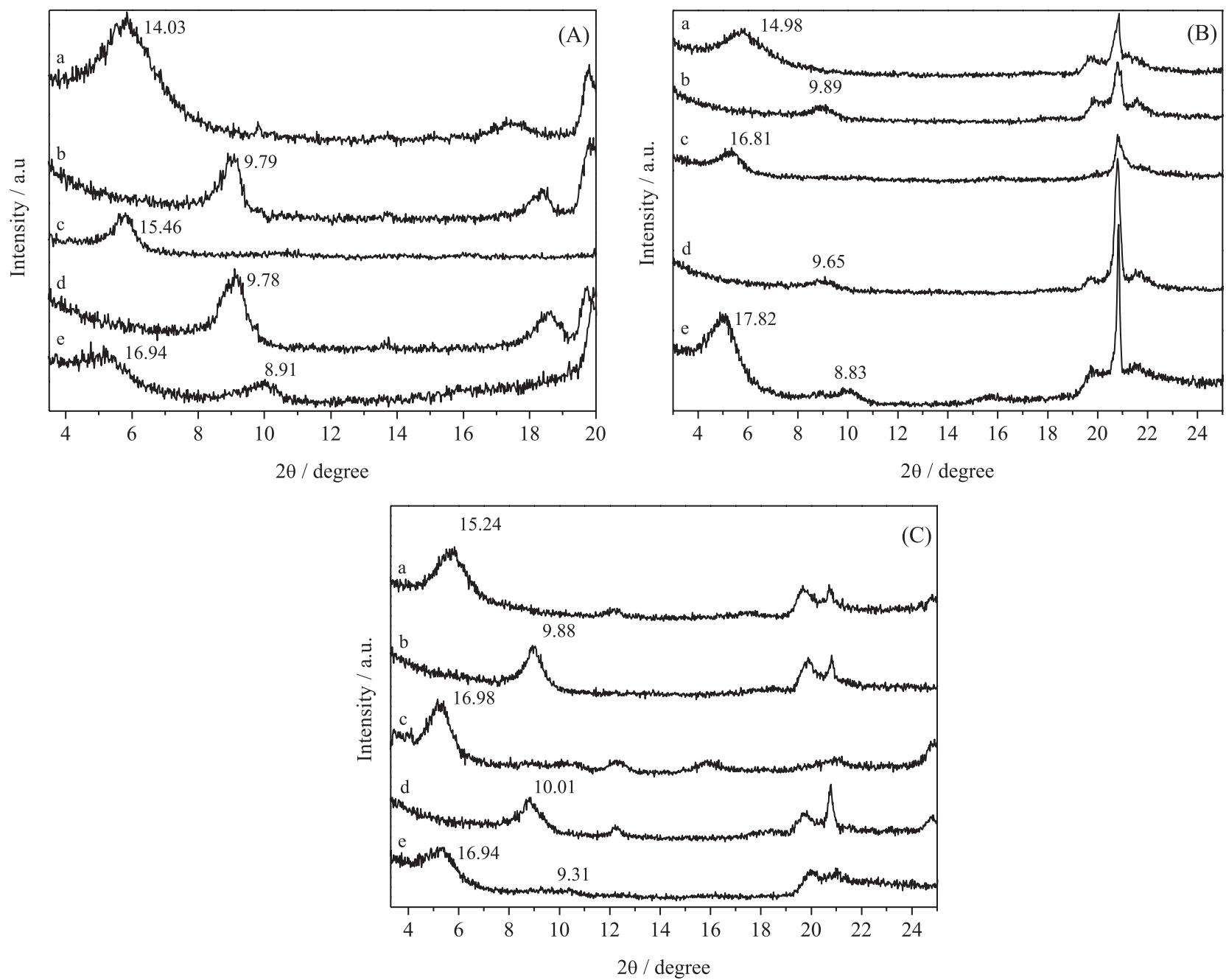

Figure 2. X-ray diffraction patterns for (A) AV; (B) AP; (C) VL. (a) Raw; (b) calcined at $550{ }^{\circ} \mathrm{C}$ for $2 \mathrm{~h}$; (c) exchanged with $\mathrm{Mg}^{2+}$ followed by ethylene glycol saturation; (d) exchanged with $\mathrm{Li}^{+}$; (e) exchanged with $\mathrm{Li}^{+}$followed by ethylene glycol saturation.

presented in Figures 2A, 2B, 2C, curves d and e. AP had large expansion of basal spacing after saturation with ethylene glycol (17.82 $\AA$ ) and a broader reflection at $8.83 \AA$, VL had expansion reaching $16.94 \AA$ and another very broad reflection at $9.31 \AA$, while AV showed broader reflections at $16.94 \AA$ and a slightly sharp one at $8.91 \AA$. These data suggested that none of the samples were pure montmorillonite, although all of them had montmorillonite in their composition and AV was the clay where montmorillonite prevailed, since its expansion in ethylene glycol was not as great as the other samples.

The identification and quantification of the elements present in clays before and after purification were determined by XRF, whose results are shown in Table 1. This technique was only used in the raw and purified samples for the purpose of mineralogical classification.

$\mathrm{AP}$ had the largest amount of $\mathrm{Si}\left(70.8 \% \mathrm{SiO}_{2}\right)$, which can be related to the amount of quartz, already shown by XRD (Figure 1B, curve a). The aluminum is attributed to the structural aluminum of the aluminum silicates and its low value (less than $22 \%$ expressed in $\mathrm{Al}_{2} \mathrm{O}_{3}$ ) can be justified by the isomorphic substituition of structural $\mathrm{Al}^{3+}$ with $\mathrm{Mg}^{2+}$, characteristic of montmorillonites. ${ }^{33}$

The content of iron, expressed as $\mathrm{Fe}_{2} \mathrm{O}_{3}$, in the samples ranged from 5.3 to $13.9 \%$, close to the values obtained in the literature ${ }^{34}$ for Brazilian smectites and Verde Lodo clay. AP and VL presented the biggest amounts of iron, which could be related to bigger substitution of $\mathrm{Al}^{3+}$ for $\mathrm{Fe}^{3+}$ in octahedral sheets, characteristic of nontronites, corroborating the XRD data, which indicated those samples had less montmorillonite than did AV.

Sodium, calcium and potassium are mainly related to interlayer cation in clay mineral structures, with sodium and calcium being the most common cations of dioctahedral smectites. ${ }^{34} \mathrm{AV}$ and $\mathrm{AP}$ presented higher values of sodium, which could indicate that these materials had more isomorphic substitution. However, sodium and potassium might not only have been due to 
Table 1. Chemical composition of clays obtained from XRF in relation to the main elements, given as mass percentage of the respective oxides

\begin{tabular}{lccccccccccc}
\hline Sample & $\begin{array}{c}\mathrm{Si} / \\
\left(\% \mathrm{~m} \mathrm{~m}^{-1}\right)\end{array}$ & $\begin{array}{c}\mathrm{Al} / \\
\left(\% \mathrm{~m} \mathrm{~m}^{-1}\right)\end{array}$ & $\begin{array}{c}\mathrm{Fe} / \\
\left(\% \mathrm{~m} \mathrm{~m}^{-1}\right)\end{array}$ & $\begin{array}{c}\mathrm{Mg} / \\
\left(\% \mathrm{~m} \mathrm{~m}^{-1}\right)\end{array}$ & $\begin{array}{c}\mathrm{K} / \\
\left(\% \mathrm{~m} \mathrm{~m}^{-1}\right)\end{array}$ & $\begin{array}{c}\mathrm{Ti} / \\
\left(\% \mathrm{~m} \mathrm{~m}^{-1}\right)\end{array}$ & $\begin{array}{c}\mathrm{Ca} / \\
\left(\% \mathrm{~m} \mathrm{~m}^{-1}\right)\end{array}$ & $\begin{array}{c}\mathrm{Na} / \\
\left(\% \mathrm{~m} \mathrm{~m}^{-1}\right)\end{array}$ & $\begin{array}{c}\mathrm{P} / \\
\left(\% \mathrm{~m} \mathrm{~m}^{-1}\right)\end{array}$ & $\begin{array}{c}\mathrm{Mn} / \\
\left(\% \mathrm{~m} \mathrm{~m}^{-1}\right)\end{array}$ & $\begin{array}{c}\mathrm{L} . \mathrm{F}^{\mathrm{a}} / \\
\left(\% \mathrm{~m} \mathrm{~m}^{-1}\right)\end{array}$ \\
\hline $\mathrm{AV}^{\mathrm{b}}$ & 53.7 & 16.8 & 5.3 & 3.1 & 0.4 & 0.4 & 1.3 & 2.8 & 0.1 & $<0.1$ & 14.7 \\
$\mathrm{PAV}^{\mathrm{c}}$ & 60.4 & 17.0 & 6.0 & 2.5 & 1.0 & 0.6 & 1.8 & 2.1 & 0.2 & $<0.1$ & 8.0 \\
$\mathrm{AP}^{\mathrm{b}}$ & 70.8 & 8.0 & 9.7 & 1.7 & 0.5 & 0.9 & 1.0 & 0.8 & 0.1 & $<0.1$ & 6.6 \\
$\mathrm{PAP}^{\mathrm{c}}$ & 57.8 & 12.0 & 9.5 & 2.5 & 0.3 & 0.8 & 0.9 & 2.7 & 0.1 & $<0.1$ & 13.0 \\
$\mathrm{VL}^{\mathrm{b}}$ & 47.0 & 16.7 & 12.3 & 3.2 & 1.4 & 1.2 & 1.1 & 0.6 & 0.1 & $<0.1$ & 16.2 \\
$\mathrm{PVL}^{\mathrm{c}}$ & 49.3 & 17.0 & 13.9 & 3.5 & 1.7 & 1.3 & 1.2 & 0.4 & 0.1 & $<0.1$ & 11.4 \\
\hline
\end{tabular}

a Loss to fire; ${ }^{\mathrm{b}}$ material analyzed without previous treatment; ${ }^{\mathrm{c}}$ material treated with $\mathrm{H}_{2} \mathrm{O}_{2}$ followed by elutriation. AV and PAV; AP and PAP; VL and PVL correspond, respectively, to materials originated from the AVL, Aço AP and Verde Lodo samples.

exchangeable cations, but also associated minerals. Thus, $\mathrm{XRF}$ analysis was performed with the clays submitted to cation exchange with $\mathrm{NaCl}$. The results confirmed that the exchangeable layer cation was $\mathrm{Na}^{+}$, so potassium was derived from associated minerals like feldspar, and calcium could be due to calcite.

The clay purification aimed to reduce organic matter and quartz in the samples. As shown in Table 1, loss to fire decreased by 29.6 and $45.6 \%$ in PVL and PAV, respectively. This parameter is related to loss of organic matter, water and carbonates decompostion, so the reduction of loss to fire values could indicate the efficiency of $\mathrm{H}_{2} \mathrm{O}_{2}$ treatment. However, PAP presented an increase of $49.2 \%$ of this value. It must be considered that the high content of quartz decreased the loss to fire in the sample before the treatment $(6.6 \%)$ and that aluminum oxide increased the loss to fire, which was 8.0 for AP and 12.0 for PAP. Although these values did not indicate changes caused by $\mathrm{H}_{2} \mathrm{O}_{2}$ purification, they showed that elutriation was able to reduce free silica in this sample. In other purified clays, silicon had a slight increase in relation to the raw ones, which does not mean low removal of free silica, since this value can also show the presence of structural silicates. ${ }^{33}$

TGA/DTG analyses supported clay characterization and these data are shown in Supplementary Information (SI) section (Figure S1). The samples showed mass loss between $50-200{ }^{\circ} \mathrm{C}$, related to adsorbed water molecules and hydration of cations. DTG curves showed two types of water interaction with the layers of AV and VL. Another mass loss, related to the dehydroxylation of the material and subsequent formation of the respective oxides, was found around $450{ }^{\circ} \mathrm{C}$ for VL (characteristic of nontronites), in the range $450-600{ }^{\circ} \mathrm{C}$ for $\mathrm{AP}$ (region that can be of nontronites and beidellites) and between 600 and $700{ }^{\circ} \mathrm{C}$ for AV (dehydroxilation of montmorillonites). In addition, decreases of mass between 250 and $350{ }^{\circ} \mathrm{C}$ were more pronounced for AP, which is related to octahedral sheet dehydration and also loss of water coordinated with interlayer cations. ${ }^{3,35}$

After this characterization, the purified clays were activated with $\mathrm{H}_{3} \mathrm{PO}_{4}$, since this is a method previously optimized by Zatta et al. ${ }^{17}$ to achieve a good catalyst for esterification reactions.

XRD also provided information about structural changes of the clays after acid activation (Figures 1A, 1B, 1C, curve c). First of all, there was a decrease in the intensity and a broadening of the 001 reflection, due to the loss of layer stacking. The basal spaces of activated samples were reduced, in AV from 14.03 to $9.51 \AA$, in AP from 14.98 to $10.66 \AA$ and in VL from 15.24 to $10.05 \AA$, due to dehydration and exchange of interlayer cations with $\mathrm{H}^{+}{ }^{8}$ These modifications were also observed by other authors, such as in the treatment of a Na-satured bentonite from Kopernika (Slovakia) with $6 \mathrm{~mol} \mathrm{~L}^{-1} \mathrm{HCl}$ solution, they used the proportion of 1:100 (weight ratio) at $95^{\circ} \mathrm{C}$ for $8 \mathrm{~h}$, the sample showed an increase from 12 to $14 \AA{ }^{36}$ and in the acid activation of a montmorillonite from the Taganskoye deposit in Kazakhstan that had a decrease from 13.9 to $13.2 \AA$ with $1 \mathrm{~mol} \mathrm{~L}^{-1} \mathrm{HNO}_{3}$ solution, when using the proportion of $1: 100$ (weight ratio) at $60{ }^{\circ} \mathrm{C}$ for 12 h. $^{25}$

Other reflections were little affected by acid activation, maintaining 060 reflection, typical of the distance between metals in octahedral sheets. The non-basal distances had presented a slower rate of decrease than the basal ones in other study too. ${ }^{36}$ This indicates low removal of octahedral cations from the clay structure, as already suggested by other authors $s^{5,8,37}$ for this type of treatment.

The modification of the clay composition after acid activation was shown by FTIR analysis (Figures 1D, 1E, $1 \mathrm{~F}$, curve $\mathrm{c}$ ). FTIR spectra of purified clays were unchanged in relation to that of raw samples (Figures 1D, 1E, 1F, curve $b$ ), whereas the activated clays (Figures 1D, 1E, 1F, curve c) continued having the bands of structural hydroxyls, mainly octahedral $\mathrm{Al}\left(3631 \mathrm{~cm}^{-1}\right), 3440 \mathrm{~cm}^{-1}$ of O-H from 
hydration water and angular deformation of $\mathrm{O}-\mathrm{H}$ from water in the interlayer region $\left(1643 \mathrm{~cm}^{-1}\right)$. The leaching of intralayer cations was indicated by the increase of the band intensity at $466 \mathrm{~cm}^{-1}$ from $\mathrm{Si}-\mathrm{O}-\mathrm{Si}$ deformation (free silica) and of the band at $1035 \mathrm{~cm}^{-1}$, the last being typical of $\mathrm{Si}-\mathrm{O}$ (tetrahedral sheets) stretching in the plane. ${ }^{29}$ The $\mathrm{Al}, \mathrm{Fe}$ and $\mathrm{Mg}$ from the sheets leaching was also described in the FTIR analyses made by other authors. ${ }^{8,16,25}$

TGA/DTG analyses (Figure S1, SI section) showed that the thermal decomposition profile of the materials indicated that the dehydration and dehydroxylation temperature ranges of the acid-activated samples were the same as for the purified and raw ones. In short, the dehydroxylation in all activated samples demonstrated that part of the clay structures was preserved after their activation, indicating low removal of octahedral cations from their structures. ${ }^{17}$ Besides that, the more defined TGA profile obtained after acid activation can indicate removal of soluble impurities. The leaching of impurities during acid activation was previously detected in the treatment of montmorillonite clay with $\mathrm{HNO}_{3} .{ }^{16}$

Textural properties of clays were analyzed by $\mathrm{N}_{2}$ adsorption-desorption and the isotherms are shown in Figure S2 (SI section). The raw, purified and activated clays presented type IV isotherms and $\mathrm{H} 3$ hysteresis, indicating mesoporous structures and particles in the form of layers with slot-shaped pores. ${ }^{30}$ Table 2 shows the increase in specific areas of the purified clays in comparison with the raw ones, probably due to removal of impurities and associated minerals, as suggested by XRF analysis. Some of the data in Table 2 are similar to that of the already reported by Dill et al. ${ }^{18}$ since these data come from different analysis of the same samples. Now, those were included in the present study to make data comparison easier.

Table 2. Textural properties of raw, purified and acid-activated clays

\begin{tabular}{lccc}
\hline Sample & $\begin{array}{c}\text { Specific area / } \\
\left(\mathrm{m}^{2} \mathrm{~g}^{-1}\right)\end{array}$ & $\begin{array}{c}\text { Pore volume / } \\
\left(\mathrm{cm}^{3} \mathrm{~g}^{-1}\right)\end{array}$ & $\begin{array}{c}\text { Average pore } \\
\text { radius / } \AA\end{array}$ \\
\hline $\mathrm{AV}^{\mathrm{a}}$ & 14 & 0.025 & 18 \\
$\mathrm{PAV}^{\mathrm{b}}$ & 51 & 0.096 & 18 \\
$\mathrm{HAV}^{\mathrm{c}}$ & 42 & 0.109 & 18 \\
$\mathrm{AP}^{\mathrm{a}}$ & 19 & 0.037 & 18 \\
$\mathrm{PAP}^{\mathrm{b}}$ & 70 & 0.111 & 18 \\
$\mathrm{HAP}^{\mathrm{c}}$ & 93 & 0.116 & 18 \\
$\mathrm{VL}^{\mathrm{a}}$ & 47 & 0.049 & 18 \\
$\mathrm{PVL}^{\mathrm{b}}$ & 81 & 0.111 & 18 \\
$\mathrm{HVL}^{\mathrm{c}}$ & 64 & 0.116 & 18 \\
\hline
\end{tabular}

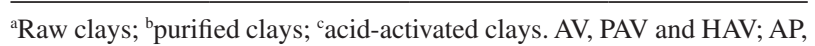
PAP and HAP; VL, PVL and HVL correspond, respectively, to materials originated from the AVL, Aço AP and Verde Lodo samples.
The specific surface area of AP was increased by acid treatment but decreased in HAV and HVL. This is an effect of octahedral cation leaching and of some structural collapse, which results in changes in the aggregation/ disaggregation of particles and is variable due to different compositions of the samples. Nevertheless, pore volume and radius were not affected to a large extent. ${ }^{7,8}$ The negligible increase in the pore volume can be related to the lower concentration and activation time used in this study $\left(0.5 \mathrm{~mol} \mathrm{~L}^{-1}\right.$ and $\left.2 \mathrm{~h}\right)$, in comparison with other studies, for instance, where concentrations of $4 \mathrm{~mol} \mathrm{~L}^{-1}$ and time of $6 \mathrm{~h}$ led to an increase of 10 times in total pore volume. ${ }^{36}$ In spite of that, the mild conditions of acid activation used in the present investigation was able to produce a useful catalyst, as it will be shown later.

The ${ }^{27} \mathrm{Al}$ NMR spectra (Figure 3 ) showed two types of aluminum, namely octahedral $\mathrm{Al}$ (with chemical shift at 2.1-4.2 ppm) and tetrahedral $\mathrm{Al}$ (with chemical shift near $55-70 \mathrm{ppm}) .38,39$

The sharp signal of octahedral Al in AP indicates its low aluminum substitution in relation to the other samples. AV had the highest content of tetrahedral Al, which suggests that it already had Lewis acidity before acid activation. Side bands (*, Figure 3 ) were broad, especially in $\mathrm{AV}$, suggesting disorder of its structure before any treatment. The broader side bands obtained in HAP in relation to other samples showed the effect of structural modification by acid, which also resulted in higher specific area (Table 2). Furthermore, leaching of octahedral aluminum in all activated materials was suggested by the reduction of the signal at 2.1-4.2 ppm. The greatest difference was found in $\mathrm{AV}$, which had a large decrease of octahedral $\mathrm{Al}$ and changes in the proportion between $\mathrm{Al}^{\mathrm{VI}}$ and $\mathrm{Al}^{\mathrm{IV}}$. 38,39

${ }^{29} \mathrm{Si}$ MAS-NMR spectra showed chemical shifts characteristic of smectites (Figure 4), with signal at $\delta-92.6$ or $-94.5 \mathrm{ppm}(\mathrm{Q} 3)$ for $\mathrm{SiO}_{4}$ groups crosslinked in the tetrahedral sheet. ${ }^{38,39}$

Q3 signals presented a significant enlargement, especially in AV samples, due to the Al substitution, already suggested by ${ }^{27} \mathrm{Al} \mathrm{NMR}$. The signal at -105.7 to $-107.2 \mathrm{ppm}$ is assigned to $\mathrm{Si}$ from three-dimensional structures Q4 or $\left[\mathrm{Si}(\mathrm{OSi})_{4}\right]$, which increased with the purification and acid activation as a result of some structural collapse, giving rise to protonated three-dimensional silica, the main building unit of this phase and responsible for the formation of clay mesopores. ${ }^{38,39}$ Similar effect was observed in the activation of a bentonite with $\mathrm{HCl}^{36}$

HAV and HVL presented some enlargement of this signal. This was because during acid activation, aluminum atoms were leached from the clay structure and imprisoned in the three-dimensional structure of silica 


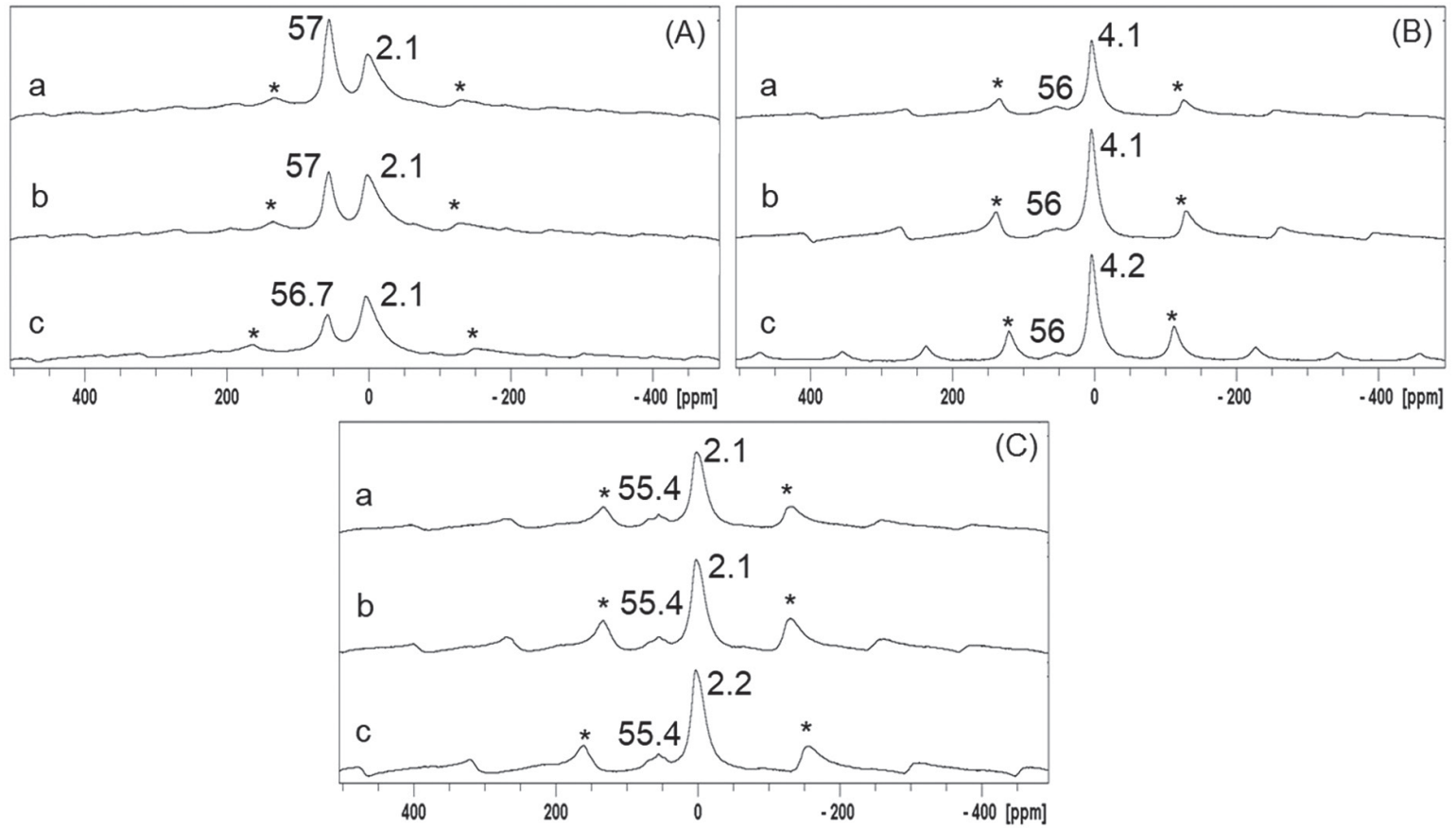

Figure 3. ${ }^{27} \mathrm{Al}$ MAS-NMR spectra of clays for (A) AV; (B) AP; (C) VL, where: (a) acid-activated clays; (b) purified clays; (c) raw clays. * indicates spinning side bands.

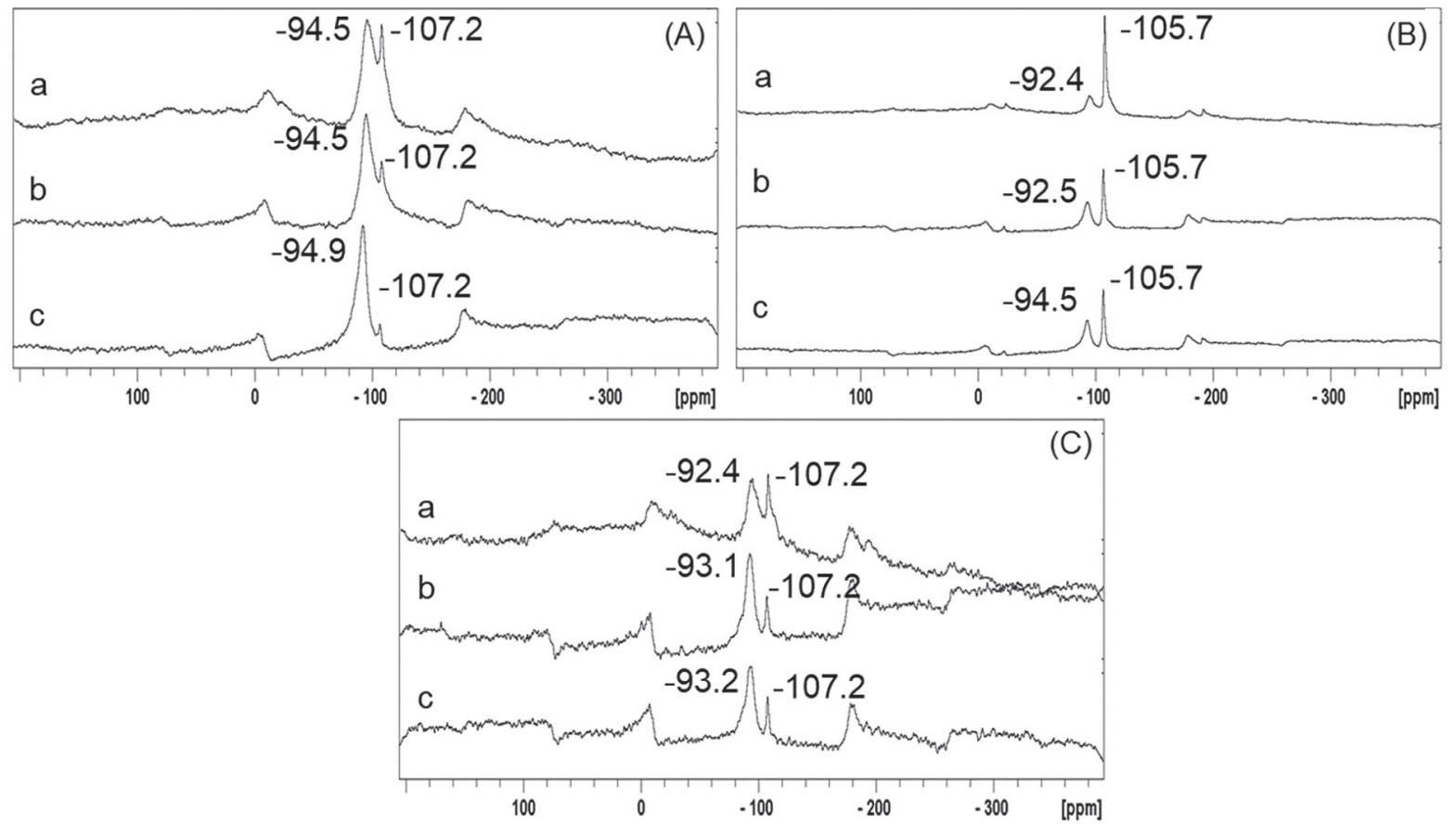

Figure 4. ${ }^{29}$ Si MAS-NMR spectra of clays for (A) AV; (B) AP; (C) VL. (a) Acid-activated; (b) purified; (c) raw clays.

that was produced by rearrangement of tetrahedral sheets at the edges of the crystals. Since this rearrangement is not uniform, the resulting structures have different morphologies, making the signals of the spectra broad. ${ }^{40}$ The signals between -102.1 and $-104.6 \mathrm{ppm}$, related to the silanol group $(\mathrm{SiO})_{3} \mathrm{SiOH}$ produced by acid activation, were almost negligible due to the mild acid treatment applied.
These groups are responsible for Brønsted-Lowry acidity and they are probably located in structural defects and edges as a result of poor ordering of the three-dimensional framework, without the possibility of crosslinking. ${ }^{38,39,41}$

The acidity of the solids was assessed by pyridine adsorption followed by FTIR analysis and the results are shown in Table 3. The Brønsted-Lowry acid sites increased 
Table 3. Acidity characterization of raw, purified and acid-activated clays

\begin{tabular}{|c|c|c|c|c|c|}
\hline Sample & $\begin{array}{c}\mathrm{C}(\mathrm{B})^{\mathrm{a}} /(\mu \mathrm{mol} \text { of } \\
\text { pyridine per } \mathrm{g} \text { of solid })\end{array}$ & $\begin{array}{c}\mathrm{C}(\mathrm{L})^{\mathrm{a}} /(\mu \mathrm{mol} \text { of } \\
\text { pyridine per } \mathrm{g} \text { of solid })\end{array}$ & $\begin{array}{c}\mathrm{D}(\mathrm{B})^{\mathrm{b}} / \\
\left(\mu \mathrm{mol} \text { per } \mathrm{m}^{2} \text { of solid }\right)\end{array}$ & $\begin{array}{c}\mathrm{D}(\mathrm{L})^{\mathrm{b}} / \\
\left(\mu \mathrm{mol} \text { per } \mathrm{m}^{2} \text { of solid }\right)\end{array}$ & Brønsted/Lewis ${ }^{c}$ \\
\hline $\mathrm{AV}$ & 0.000 & 4.087 & 0.000 & 0.288 & no B sites \\
\hline PAV & 2.460 & 1.731 & 0.048 & 0.034 & 1.41 \\
\hline HAV & 1.856 & 1.233 & 0.044 & 0.029 & 1.52 \\
\hline $\mathrm{AP}$ & 0.000 & 4.535 & 0.000 & 0.241 & no B sites \\
\hline PAP & 0.000 & 3.639 & 0.000 & 0.052 & no B sites \\
\hline HAP & 1.668 & 2.218 & 0.018 & 0.024 & 0.75 \\
\hline VL & 6.598 & 6.578 & 0.141 & 0.141 & 1.00 \\
\hline PVL & 3.896 & 3.857 & 0.048 & 0.048 & 1.00 \\
\hline HVL & 2.983 & 2.883 & 0.047 & 0.045 & 1.04 \\
\hline
\end{tabular}

a Concentration of Brønsted or Lewis acid sites; ${ }^{b}$ density of Brønsted or Lewis acid sites; ' $r a t i o$ between Brønsted and Lewis acid site densities. Capital letters C, D, B and L correspond to concentration, density, Brønsted and Lewis, respectively. AV, PAV and HAV; AP, PAP and HAP; VL, PVL and HVL correspond, respectively, to materials originated from the AVL, Aço AP and Verde Lodo samples.

in all cases of activated samples, which is a result of the crystal edges' opening and breaking of the bonds found in this region, compensated by $\mathrm{OH}$ groups, leading to $\equiv \mathrm{Si}-\mathrm{OH}$ (silanol) acid sites, for example. Also, Brønsted sites can be due to compensating cations, but they are found in the interlayer, which hinders their access and use for catalysis. ${ }^{8,42}$

Lewis acid sites are due to coordinatively unsaturated $\mathrm{Al}^{3+}$ and $\mathrm{Mg}^{2+}$ at the edges. ${ }^{42}$ Lewis acid sites were present in the clays before treatment and their concentrations only slightly changed after purification and activation. On the other hand, the density of these sites diminished as an effect of the increase of the specific areas of the treated clays in relation to the raw ones, which had more dispersed active sites.

The improvement of Brønsted acid sites and the decrease of Lewis acid sites was great in the case of the activation of a smectite soil clay from Cameroon with

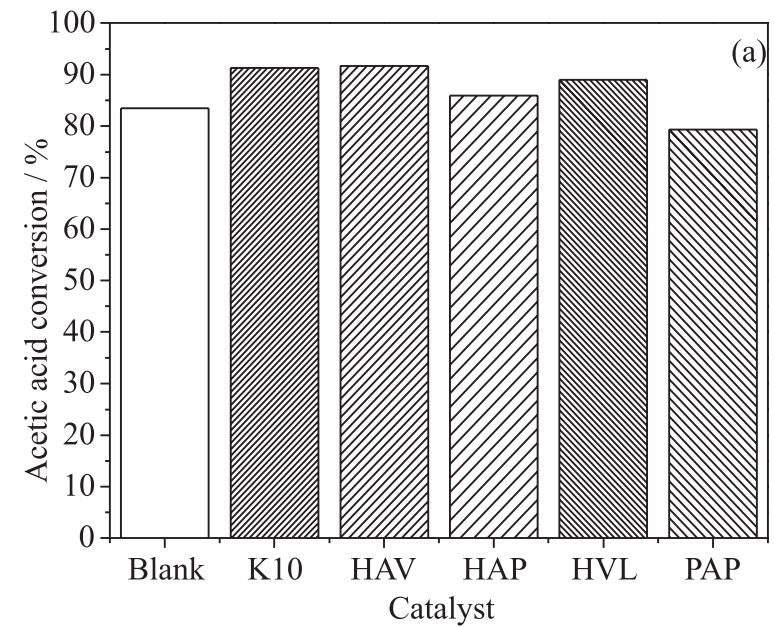

$1 \mathrm{~mol} \mathrm{~L}^{-1}$ of the acids $\mathrm{H}_{2} \mathrm{SO}_{4}$ and $\mathrm{HCl}$ in the proportion of 1:5 (g of clay:mL of solution) at $97{ }^{\circ} \mathrm{C}$ for $4 \mathrm{~h} .{ }^{43}$ The Brønsted acid sites increase was also observed in the treatment of kaolinites with $\mathrm{HCl}^{44}$

\section{Catalytic properties of clays modified with $\mathrm{H}_{3} \mathrm{PO}_{4}$}

In the reactions between methanol and carboxylic acids carried out using HAV, HAP and HVL as catalysts, lower values of conversion were observed for lauric acid in comparison to acetic acid (Figure 5), due to the decrease in the reactivity of the carboxylic acid with its increase in hydrocarbon chain. The kinetics of acetic acid esterification is more favored in relation to that of lauric acid and the chemical equilibrium could be reached faster. Furthermore, the greater miscibility between acetic acid and methanol also facilitated the reaction and the polarity

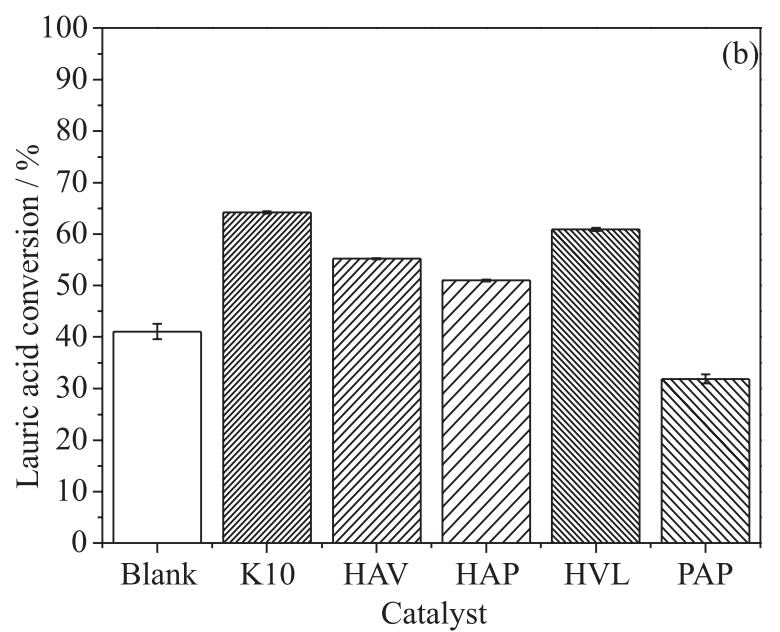

Figure 5. (a) Percentage of acetic acid conversion in the esterification with methanol; (b) percentage of lauric acid conversion in the esterification with methanol. Reaction conditions: methanol:carboxylic acid molar ratio of 3:1, stirring of $500 \mathrm{rpm}, 5 \%$ of catalyst in relation to the carboxylic acid mass, at $120^{\circ} \mathrm{C}$ for $2 \mathrm{~h}$. 
of these reactants aided the solvation of the transition state of the esterification. ${ }^{45}$

The higher conversions attained by using acid-activated clays can be attributed to the Brønsted acid sites $(\mathrm{OH}$ groups) of the catalysts, since the Brønsted acid protonates the oxygen of carbonyl. The protonated substance has a resonance hybrid with formal positive charge in the carbonyl carbon of the carboxylic acids (Figure 6a), which favors the nucleophilic attack by methanol. This occurs easily, since the small size of the proton does not imply in strong steric hindrance to its approach towards carbonyl. In addition, Lewis acids of the clays (like $\mathrm{Al}^{3+}$ and $\mathrm{Mg}^{2+}$ ) can contribute to the ester obtaining too, because Lewis acid coordinates itself to the oxygen of carbonyl, reducing electron density and it also results in the formation of a resonance hybrid with formal positive charge in the carbonyl carbon (Figure 6b) that facilitate methanol attack. The coordination between the Lewis acid sites of the catalyst and the carbonyl oxygen of the carboxylic acid is aided due to their characteristics based on Pearson theory, $\mathrm{Al}^{3+}$ and $\mathrm{Mg}^{2+}$ are hard acids and the oxygen is a hard base, so there is a good interaction between hard-hard species. In the coordination of Lewis acids there is as higher influence of steric hindrance, which is more prominent in the case of lauric acid, leading to a slower kinetics of esterification, resulting in the less conversion values observed. ${ }^{45,46}$

(a)
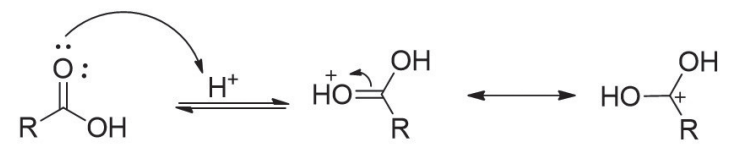

(b)
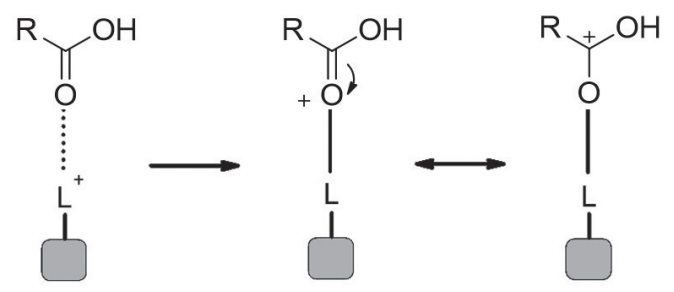

Figure 6. (a) Protonation of the carbonyl oxygen of a carboxylic acid by a Brønsted acid and formation of the specie with partial positive charge in the carbonyl carbon; (b) coordination of the Lewis acid with the carbonyl oxygen of a carboxylic acid and formation of the specie with partial positive charge in the carbonyl carbon (adapted from reference 46).

Figure 5 show that the conversions with PAP were below the blanks, which can be explained because this material had no Brønsted acidity (Table 3 ) and thus the nonactivated solid hindered the reaction process by hampering the collision of the reactant molecules.

When considering the catalysts produced in this work, the acid conversion increased in relation to the blank reaction. In the case of acetic acid esterification, this result agreed well with the order of Brønsted/Lewis acid site ratio in the solids ( $\mathrm{HAV}>\mathrm{HVL}>\mathrm{HAP}>\mathrm{PAP}$ ), suggesting that Brønsted acid sites were the most important for the improvement of acetic acid esterification with methanol. On the other hand, for lauric acid esterification, the order of conversion agreed only with the density of Brønsted acid sites: HVL $\left(0.047 \mu \mathrm{mol} \mathrm{m}{ }^{-2}\right)>\operatorname{HAV}\left(0.044 \mu \mathrm{mol} \mathrm{m}{ }^{-2}\right)>$ $\operatorname{HAP}\left(0.018 \mu \mathrm{mol} \mathrm{m}^{-2}\right)>$ PAP (no Brønsted site). Such data indicated the greater activity of HAV and HVL, the catalysts with the lowest specific areas compared to HAP, although they had the greatest density of Brønsted acid sites. Also, it could be considered that the activities of the catalysts in lauric acid reaction was different from those observed in acetic acid reaction due to the modification of phase composition on the catalyst by acetic acid, since it can be enough to promote the leaching of $\mathrm{Al}^{3+}$ from framework of clay. ${ }^{47}$ Chaari et al. ${ }^{48}$ also concluded that the main variable affecting the catalytic activity of different commercial acid clays (KSF/O, KSF, KP10 and K10) in the esterification (of ethylene glycol with oleic acid) was acidity, which was measured as $\mathrm{pH}$ value of the solid aqueous suspensions. The authors reported that other physical properties, such as specific area and average pore diameter, had no effect on the conversion of oleic acid.

Indeed, this study showed the influence of the acidity in the catalytic activity of the clays. However, since the mechanism of esterification using acid clay as catalyst could involve any acid site present in the structure (Brønsted or Lewis sites), the present study is of utmost importance, since it showed that Brønsted acid sites were the most important for the increase of esterification. ${ }^{6,8}$ Furthermore, HAV and HVL had a response very similar to that obtained with $\mathrm{K} 10$, which is very promising since the use of the raw modified clay instead of a commercial solid catalyst could reduce the cost of the esterification processes. Also, aiming to reduce process costs, the recovery and reuse of the catalyst HAV was performed.

After one reaction cycle, HAV was characterized by XRD and FTIR (Figure 7). Used HAV presented similar behavior to fresh HAV, since there was no apparent modification in the solid structure. This showed the stability of the catalyst in the reaction conditions analyzed. Also, the capacity of HAV reuse was indicated by the maintenance of carboxylic acid conversion, shown in Table 4, which corroborates the use of this solid as an efficient and cheap catalyst for the methanolysis of acetic and lauric acid.

\section{Conclusions}

Characterization of three raw Brazilian clays 

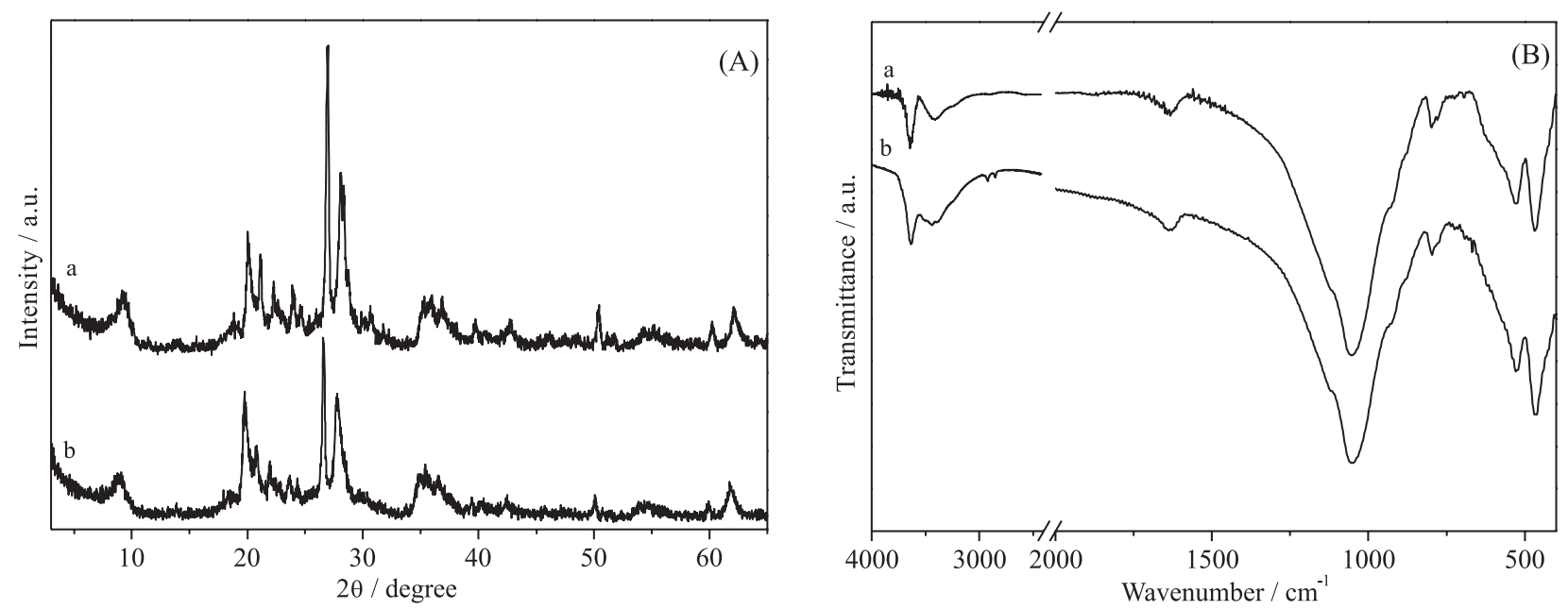

Figure 7. (A) X-ray diffraction patterns and (B) Fourier transform infrared spectra, respectively for HAV (a) before use and (b) after use.

Table 4. Percentage of lauric or acetic acid conversion in the esterification with methanol obtained in the first and second reaction cycle using HAV

\begin{tabular}{lccc}
\hline Carboxylic acid & Cycle of use & Conversion $^{\mathrm{a}}$ \% & Gain $^{\mathrm{b}}$ / p.p. \\
\hline Acetic & 1 & $91.3 \pm 0.1$ & 7.8 \\
Acetic & 2 & $91.4 \pm 0.2$ & 7.9 \\
Lauric & 1 & $55.2 \pm 0.2$ & 14.0 \\
Lauric & 2 & $52.0 \pm 1.7$ & 10.9 \\
\hline
\end{tabular}

a Percentage of lauric or acetic acid conversion; ${ }^{\mathrm{b}}$ conversion gains in relation to the blank reaction, expressed in percentage points (p.p.).

showed they are composed mainly by dioctahedral smectites, containing phases with different proportions of montmorillonite, nontronite and beidellite. The three clays were different in composition, so the acid activation resulted in distinct changes in their structure and acidity. In addition, the significance of the acid activation to improve the catalytic activity of the solids was shown by the poor result of the reaction performed with PAP. The strong influence of the Brønsted acid sites in the catalysis of acetic or lauric acid esterification with methanol was suggested, since higher Brønsted/Lewis acid site ratio resulted in better acid conversion. The maximum acid conversions obtained were of 92 and 64\%, for acetic acid using HAV and for lauric acid using HVL, respectively, which was related to their biggest Brønsted/Lewis acid site ratio (1.52 for HAV and 1.04 for HVL). Moreover, HAV and HVL presented carboxylic acid conversion similar to that obtained with a commercial catalyst (montmorillonite $\mathrm{K} 10)$. HAV was used in a second reaction cycle without apparent loss of activity, achieving 91.4 and $52.0 \%$ of acetic and lauric acid conversions, respectively, in the second use. These results point to its potential as an inexpensive and more environmentally friendly catalyst for the esterification process.

\section{Supplementary Information}

TGA and DTG curves of clays and isotherms of raw, purified and acid-activated clays analyzed by $\mathrm{N}_{2}$ adsorption-desorption are available free of charge at https://jbcs.sbq.org.br as PDF file.

\section{Acknowledgments}

This study was financed in part by the Coordenação de Aperfeiçoamento de Pessoal de Nível Superior, Brazil (CAPES), finance code 001, CNPq (FW projects 300988/2019-2, 400117/2016-9) and FINEP. L. P. D. and D. M. K. thank CNPq and CAPES for the PhD scholarships.

\section{Author Contributions}

Laís P. Dill was responsible for the conceptualization, data curation, investigation, writing original draft, review and editing; Débora M. Kochepka for the conceptualization, investigation and writing review and editing; Larissa $\mathrm{L}$. Lima for the data curation, software and writing review and editing; Alexandre A. Leitão for the data curation, software and writing review and editing; Fernando Wypych for the conceptualization, project administration, resources and writing review and editing; Claudiney S. Cordeiro for the conceptualization, project administration, resources and writing review and editing.

\section{References}

1. Demarquette, N. R.; Carastan, D.; Valera, T. S. In Recent Advances in Polymer Nanocomposites; Thomas, S.; Zaikov, G., eds.; Nova Science Publishers: New York, USA, 2008, p. 327.

2. Vaccari, A.; Appl. Clay Sci. 1999, 14, 161. 
3. Caglar, B.; Afsin, B.; Tabak, A.; Eren, E.; Chem. Eng. J. 2009, 149, 242.

4. Zhou, C. H.; Appl. Clay Sci. 2011, 53, 87.

5. Komadel, P.; Madejova, J. In Handbook of Clay Science; Bergaya, F.; Theng, B. K. G.; Lagaly, G., eds.; Elsevier: Amsterdam, Netherlands, 2006, p. 263.

6. Steudel, A.; Batenburg, L. F.; Fischer, H. R.; Weidler, P. G.; Emmerich, K.; Appl. Clay Sci. 2009, 44, 105.

7. Ramesh, S.; Bhat, Y. S.; Prakash, B. S. J.; Clay Miner. 2012, 47, 231.

8. Komadel, P.; Appl. Clay Sci. 2016, 131, 84.

9. Chitnis, S. R.; Sharma, M.; React. Funct. Polym. 1997, 32, 93.

10. Varma, R. S.; Tetrahedron 2002, 58, 1235.

11. Hart, M. P.; Brown, D. R.; J. Mol. Catal. A: Chem. 2004, 212, 315.

12. Vilcocq, L.; Spinola, V.; Moniz, P.; Duarte, L. C.; Carvalheiro, F.; Fernandes, C.; Castilho, P.; Catal. Sci. Technol. 2015, 5, 4072.

13. Ugochukwu, U. C.; Fialips, C. I.; Chemosphere 2017, 178, 65.

14. Rezende, M. J. C.; Pereira, M. S. C.; Santos, G. F. N.; Aroeira, G. O. P.; Albuquerque Jr., T. C.; Suarez, P. A. Z.; Pinto, A. C.; J. Braz. Chem. Soc. 2012, 23, 1209.

15. Zatta, L.; Paiva, E. J. M.; Corazza, M. L.; Wypych, F.; Ramos, L. P.; Energy Fuels 2014, 28, 5834.

16. Timofeeva, M. N.; Panchenko, V. N.; Krupskaya, V. V.; Gil, A.; Vicente, M. A.; Catal. Commun. 2017, 90, 65.

17. Zatta, L.; Ramos, L. P.; Wypych, F.; Appl. Clay Sci. 2013, 80-81, 236.

18. Dill, L. P.; Kochepka, D. M.; Melinski, A.; Wypych, F.; Cordeiro, C. S.; React. Kinet., Mech. Catal. 2019, 127, 991.

19. Greene-Kelly, R.; J. Soil Sci. 1963, 4, 233.

20. Lim, C. H.; Jackson, M. L.; Clay Clay Miner. 1986, 34, 346.

21. Emeis, C. A.; J. Catal. 1993, 141, 347.

22. Chakraborty, B.; Viswanathan, B.; Catal. Today 1999, 49, 253.

23. American Oil Chemists' Society (AOCS); Official Method Ca 5a-40: Free Fatty Acids in Crude and Refined Fats and Oils; AOCS: Urbana, USA, 2017.

24. GraphPad Prism, version 5.01; GraphPad Software, Inc., San Diego, USA, 1989.

25. Krupskaya, V. V.; Zakusin, S. V.; Tyupina, E. A.; Dorzhieva, O. V.; Zhukhlistov, A. P.; Belousov, P. E.; Timofeeva, M. N.; Minerals 2017, 7, 49 .

26. Chipera, S. J.; Bish, D. L.; Clay Clay Miner. 2001, 49, 398.

27. Krupskaya, V.; Novikova, L.; Tyupina, E.; Belousov, P.; Dorzhieva, O.; Zakusin, S.; Kim, K.; Roessner, F.; Badetti, E.; Brunelli, A.; Belchinskaya, L.; Appl. Clay Sci. 2019, 172, 1.
28. Deer, W. A.; Howie, R. A.; Zussman, J.; An Introduction to the Rock-Forming Minerals; John Wiley \& Sons: New Jersey, USA, 1967.

29. Madejová, J.; Vib. Spectrosc. 2003, 31, 1.

30. Madejová, J.; Komadel, P.; Clay Clay Miner. 2001, 49, 410.

31. Tyagi, B.; Chudasama, C. D.; Jasra, R. V.; Spectrochim. Acta, Part A 2006, 64, 273.

32. Köster, H. M.; Ehrlicher, U.; Gilg, H. A.; Jordan, R.; Murad, E.; Onnich, K.; Clay Miner. 1999, 34, 579.

33. Santos, P. S.; Tecnologia de Argilas, vol. 2; Edgar Blucher: São Paulo, Brazil, 1975.

34. Leite, S. M.; Colodete, C. H. A.; Dieguez, L. C.; San Gil, R. A. S.; Quim. Nova 2000, 23, 297.

35. Valenzuela-Días, F. R.; Santos, P. S.; Quim. Nova 2001, 24, 345.

36. Pentrák, M.; Hronský, V.; Pálková, H.; Uhlík, P.; Komadel, P.; Madejová, J.; Appl. Clay Sci. 2018, 163, 204.

37. Kumar, P.; Jasra, R. V.; Bhat, T. S. G.; Ind. Eng. Chem. Res. 1995, 34, 1440.

38. Tkáč, I.; Komadel, P.; Müller, D.; Clay Miner. 1994, 29, 11.

39. Ashbrook, S. E.; Dawson, D. M. In Nuclear Magnetic Resonance, vol. 45; Ramesh, V., ed.; RSC: Cambridge, UK, 2016, p. 1.

40. Woessner, D. E.; Am. Mineral. 1989, 74, 203.

41. Yan, Z.; Ma, D.; Zhuang, J.; Liu, X.; Liu, X.; Han, X.; Bao, X.; Chang, F.; Xu, L.; Liu, Z.; J. Mol. Catal. A: Chem. 2003, 194, 153.

42. Lambert, J. F.; Poncelet, G.; Top. Catal. 1997, 4, 43.

43. Ndé, H. S.; Tamfuh, P. A.; Clet, G.; Vieillard, J.; Mbognou, M. T.; Woumfo, E. D.; Heliyon 2019, 5, e02926.

44. Timofeeva, M. N.; Panchenko, V. N.; Volcho, K. P.; Zakusin, S. V.; Krupskaya, V. V.; Gil, A.; Mikhalchenko, O. S.; Vicente, M. A.; J. Mol. Catal. A: Chem. 2016, 414, 160.

45. Anslyn, E. V.; Dougherty, D. A.; Modern Physical Organic Chemistry, $2^{\text {nd }}$ ed.; University Science Books: Mill Valley, USA, 2006.

46. Cordeiro, C. S.; Silva, F. R.; Wypych, F.; Ramos, L. P.; Quim. Nova 2011, 34, 477.

47. Mahmoud, S.; Saleh, S.; Clay Clay Miner. 1999, 47, 481.

48. Chaari, A.; Neji, S. B.; Frikh, M. H.; J. Oleo Sci. 2017, 66, 455.

Submitted: April 13, 2020

Published online: August 11, 2020 